\title{
Acúmulo de minerais em Aechmea blanchetiana (Baker) L.B. Smith (Bromeliaceae), contaminadas com zinco em cultivo in vitro
}

\author{
Maria Cristina Tessari Zampieri1 ${ }^{1,4}$, Mitiko Saiki ${ }^{1}$, Armando Reis Tavares $^{2}$ e \\ Gladys Flávia de Albuquerque Melo de Pinna ${ }^{3}$
}

Recebido: 2.03.2012; aceito: 19.07.2012

\begin{abstract}
Accumulation of mineral nutrients in Aechmea blanchetiana (Baker) L.B. Smith (Bromeliaceae) contaminated with zinc during in vitro culture). The aim of this work was to evaluate the absorption and translocation of Ca, Co, Fe, $\mathrm{K}$ and $\mathrm{Zn}$ in plants of Aechmea blanchetiana grown in in vitro conditions contaminated with $\mathrm{Zn}(0.0,0.18,1.8,18$ and $180 \mathrm{mg} \mathrm{Zn} \mathrm{L}^{-1}$ ). After 16 weeks of in vitro culture, root and shoot systems (leaves and stem) were separated, dried for dry mass measurements and neutron activation analysis (NAA). The results showed that the relative standard deviations were $9.1 \%$ and errors were less than $12.9 \%$. The results obtained for A. blanchetiana indicated that $\mathrm{Zn}$ altered the absorption and translocation of $\mathrm{Ca}, \mathrm{Co}, \mathrm{Fe}, \mathrm{K}$ and $\mathrm{Zn}$. The species showed high values of zinc in root and aerial systems possibly indicating bioaccumulation of the element.
\end{abstract}

Key words: bioaccumulator, neutron activation analysis, translocation index

RESUMO - (Acúmulo de minerais em Aechmea blanchetiana (Baker) L.B. Smith (Bromeliaceae), contaminadas com zinco em cultivo in vitro). Com o objetivo de estudar a absorção e translocação de $\mathrm{Ca}, \mathrm{Co}, \mathrm{Fe}, \mathrm{K}$ e $\mathrm{Zn}$ em Aechmea blanchetiana, plantas foram cultivadas in vitro em meios de cultivo contendo concentrações de Zn $\left(0,0 ; 0,18 ; 1,8 ; 18\right.$ e $\left.180 \mathrm{mg} \mathrm{Zn} \mathrm{L}^{-1}\right)$. Após 16 semanas de cultivo, os sistemas aéreo e radicular foram separados e determinadas à massa seca para massa de matéria seca e para a análise por ativação com nêutrons (AAN). O procedimento consistiu em irradiar amostras e padrões no reator nuclear de pesquisa IEA-R1 por $16 \mathrm{~h}$ para análise por espectrometria de raios gama. O controle dos resultados foi avaliado por meio das análises dos materiais de referência certificados, com desvios padrão relativo de $9,1 \%$ e erros inferiores a 12,9 \%. Os resultados das determinações dos elementos mostraram que o Zn alterou absorção e translocação de $\mathrm{Ca}, \mathrm{Co}, \mathrm{Fe}, \mathrm{K}$ e $\mathrm{Zn}$. A espécie apresentou alta quantidade de $\mathrm{Zn}$ nos sistemas aéreo e radicular indicando, possivelmente, ser bioacumuladora desse elemento.

Palavras-chave: análise por ativação com nêutrons, bioacumuladora, índice de translocação

\section{Introdução}

Os metais pesados são componentes da biosfera, de ocorrência natural nos solos e plantas, contudo como consequências de ações antrópicas, os seus níveis têm aumentado no meio ambiente (Schüürmann \& Markert 1998). O excesso de $\mathrm{Cu}$ ou $\mathrm{Zn}$ presente na água ou no solo pode ser de ações antrópicas tais como as aplicações de produtos fitoquímicos (fungicidas, pesticidas e inseticidas), adubações na agricultura (Marsola et al. 2005), resíduos sólidos industriais, mineradoras (Cunha et al. 2008), descarte de materiais metalúrgico, eletrônico, de bateria, pigmentos para tintas e da indústria de plásticos (Zeitouni 2003).

As raízes das plantas, auxiliado pelos agentes quelantes produzidos pelas plantas e as alterações induzidas pela planta no $\mathrm{pH}$ e nas reações redox, são capazes de solubilizare absorver micronutrientes a níveis muito baixos no solo, mesmo a partir de precipitados insolúveis; estando, esses mesmos mecanismos envolvidos na absorção, translocação e armazenamento de elementos tóxicos (Tangahu et al. 2011).

1. Instituto de Pesquisas Energéticas e Nucleares, Avenida Professor Lineu Prestes 2242, 05508-000 São Paulo, SP, Brasil

2. Instituto de Botânica, Núcleo de Pesquisas em Plantas Ornamentais, Caixa Postal 68041, 04045-972 São Paulo, SP, Brasil

3. Universidade de São Paulo, Instituto de Biociências, Departamento de Botânica, Rua do Matão 321 Travessa 14, 05508-090 São Paulo, SP, Brasil

4. Autor para correspondência: cristessari@gmail.com 
Concentrações de zinco abaixo de 15-20 $\mu \mathrm{g} \mathrm{Zn}$ por massa de matéria seca de folha são consideradas como deficiência do mineral e concentrações acima 100-300 $\mu \mathrm{g} Z \mathrm{Zn}$ por massa de matéria seca são fitotóxicas (Marschner 1995). A toxidez por zinco pode ser induzida rapidamente em plantas não tolerantes, tendo como principal característica a inibição do crescimento radicular. A clorose das folhas também pode ser induzida pela toxidez do zinco, na maioria dos casos pela deficiência de magnésio ou ferro, devido a competição dos sítios entre os elementos (Navarro 2003).

Espécies do gênero Tillandsia (Bromeliaceae) são usualmente utilizadas como espécies biomonitoras de metais pesados presentes em poluição aérea, entretanto em estudo realizado por Elias et al. (2006) comparando a capacidade de absorção de diversas espécies de bromélias, concluiu que a espécie Canistropsis billbergioides (Schult. F.) Leme apresentou maior índice de acumulação, sendo indicada para avaliação da composição química em florestas tropicais; concluindo que, condições ambientais como luminosidade, depósito de serrapilheira e composição química atmosférica contribuíram para o maior acúmulo de elementos químicos nas folhas desta espécie, em relação a Tillandsia. A bromélia Aechmea blanchetiana (Baker) L.B. Smith, é uma espécie nativa do Brasil, de hábito herbáceo ou epifítico, as plantas formam touceiras com 60 a $90 \mathrm{~cm}$ de altura, a folhagem é verde clara e se apresenta em forma de roseta formando tanque (Lorenzi \& Souza 2001). A espécie, devido ao seu uso paisagístico está adaptada a todas as regiões do Brasil e mostrou-se responsiva a aplicação de nutrientes (Kanashiro 2009) e metais pesados (Giampaoli et al. 2012), em condições de cultivo in vitro.

O objetivo do presente estudo foi aplicar o método de análise por ativação com nêutrons na determinação das concentrações de $\mathrm{Ca}, \mathrm{Co}, \mathrm{Fe}, \mathrm{K}$ e Zn para cálculo do índice de translocação desses elementos, em plantas de Aechmea blanchetiana (Bromeliaceae) cultivadas in vitro em meios de cultura contaminado com $\mathrm{Zn}$. Para a avaliação da exatidão e precisão dos resultados foram analizados os materiais de referência NIST SRM 1547 Peach Leaves e INCT-TL-1 Tea Leaves provenientes do National Institute of Standards and Technology (INCT).

\section{Material e métodos}

Obtenção da Aechmea blanchetiana e seu tratamento para as análises - $\mathrm{O}$ experimento de cultivo in vitro foi realizada no Laboratório do Núcleo de Pesquisas em Plantas Ornamentais do Instituto de Botânica, São Paulo, SP. As plantas foram obtidas da germinação in vitro de sementes de $A$. blanchetiana, em meio de cultivo MS modificado (Murashige \& Skoog 1962), pelo período de 10 meses. Após esse período, realizou-se o preparo dos explantes com a poda das folhas na região mediana e poda total das raízes; sendo, inoculadas nos tratamentos. Foram realizados diferentes tratamentos com $\mathrm{Zn}\left(\mathrm{ZnSO}_{4}\right)$ nas concentrações de 0 (controle); 0,18 (concentração máxima de $\mathrm{Zn}$ permitido no índice do padrão de potabilidade nas águas doces Classe I, de acordo com a resolução 357 do Conselho Nacional do Meio Ambiente (CONAMA, 2005)); 1,8; 18 e $180 \mathrm{mg} \mathrm{Zn} \mathrm{L}^{-1}$. As culturas permaneceram em sala de cultivo em temperatura de $25 \pm 2{ }^{\circ} \mathrm{C}$, fotoperíodo de $16 \mathrm{~h}$ dia e $36 \mu \mathrm{mol} \mathrm{m}^{-2} \mathrm{~s}^{-1}$ de radiação fotossinteticamente ativa (PAR). Após 16 semanas, foram retiradas 30 plantas para cada tratamento realizado, incluindo também o material controle (testemunha). O material foi lavado por três vezes em água deionizada, e separado em sistemas aéreo (folha e caule) e radicular. As amostras foram submetidas à secagem a temperatura de $42{ }^{\circ} \mathrm{C}$ por $48 \mathrm{~h}$ em estufa de circulação forçada de ar e, posteriormente, trituradas utilizando liquidificador com lâminas de titânio.

Procedimentos para análise por ativação com nêutrons (AAN) - Os padrões sintéticos dos elementos foram preparados, a partir de soluções diluídas contendo um ou mais elementos das soluções certificadas da Spex Certiprep USA. Alíquotas de $50 \mu \mathrm{L}$ das soluções diluídas foram pipetadas sobre tiras de papel de filtro Whatman n. 40. As massas dos elementos nos padrões sintéticos foram $\mathrm{Ca}=501,86 \mu \mathrm{g}$; $\mathrm{Co}=150,15 \mu \mathrm{g}$; $\mathrm{Fe}=351,12 \mu \mathrm{g} ; \mathrm{K}=500,8 \mu \mathrm{g}$ e $\mathrm{Zn}=35,97 \mu \mathrm{g}$. Após a secagem, as tiras de papel foram acondicionadas em invólucros de plásticos, previamente lavados com solução de ácido nítrico diluído e água purificada MILLIQ, e secos a temperatura ambiente.

$\mathrm{O}$ procedimento da AAN consistiu em irradiar de 150 a $200 \mathrm{mg}$ das amostras do sistema aéreo, radicular e materiais de referência em invólucros de polietileno. As amostras e padrões sintéticos dos elementos foram envoltos em folhas de alumínio e colocados dentro de dispositivo cilíndrico de alumínio para irradiação no reator nuclear de pesquisa IEA-R1 do IPEN-CNEN/ SP. O tempo para irradiação utilizado foi de $16 \mathrm{~h}$ sob fluxo de nêutrons térmicos 
de $4 \times 10^{12} \mathrm{n} \mathrm{cm}^{-2} \mathrm{~s}^{-1}$ a $5 \times 10^{12} \mathrm{n} \mathrm{cm}^{-2} \mathrm{~s}^{-1}$. Depois de adequados os tempos de decaimento, de cerca de cinco dias, foram realizadas as medições das atividades gama dos radioisótopos formados, usando o detector semicondutor de Ge hiperpuro acoplado a placa ACE8K (EG \& G ORTEC), microcomputador e sistema eletrônico associado. O sistema foi verificado diariamente por medição com fonte mista de ${ }^{57} \mathrm{Co} e$ ${ }^{60} \mathrm{Co}$.

As contagens foram realizadas de cinco a oito dias após o término da irradiação por $5.400 \mathrm{~s}$ para os padrões e $20.000 \mathrm{~s}$ para as amostras, na primeira contagem. Na segunda contagem, após o tempo de decaimento de 13 a 18 dias da irradiação, foram utilizados os tempos de contagem de $5.400 \mathrm{~s}$ para os padrões e de $50.000 \mathrm{~s}$ para as amostras.

O processamento dos espectros gama foi realizado com o programa de computação VISPECT2, obtendo-se as energias e áreas dos picos dos espectros gerados. A identificação dos radioisótopos ${ }^{47} \mathrm{Ca},{ }^{60} \mathrm{Co}$, ${ }^{59} \mathrm{Fe},{ }^{42} \mathrm{~K}$ e ${ }^{65} \mathrm{Zn}$ foi realizada pelas energias dos raios gama e meia vida. As concentrações dos elementos nas amostras foram calculadas pelo método comparativo (De Soete et al. 1972).

Controle de qualidade dos resultados - A exatidão e precisão dos resultados foram avaliadas pela análise dos materiais de referência certificados INCT-TL-1 Tea Leaves (INCT 2002) e NIST SRM 1547 Peach Leaves (NIST 2003). A determinação das percentagens de umidade dos materiais foi realizada pesando-se cerca de $200 \mathrm{mg}$ de material para secagem $(16 \mathrm{~h}$ a temperatura de $85^{\circ} \mathrm{C}$ ). Na secagem foram obtidos os valores 10,06\% para NIST SRM 1547 Peach Leaves e 7,98\% para INCT-TL-1 Tea Leaves utilizados nos cálculos das concentrações dos elementos na base seca do material.

Os valores $Z$-score ${ }_{i}$ foram calculados para os elementos que apresentaram valores de referência nos certificados, usando a relação (IAEA, 2001):

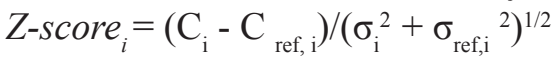

$\left(\mathrm{C}_{\mathrm{i}}\right.$ : concentração do elemento i obtido na análise do material de referência; $\mathrm{C}_{\text {ref,i }}$ : concentração certificada para o elemento $i ; \sigma_{i}$ : desvio padrão da concentração obtida para o elemento i na análise do material de referência; $\sigma_{\text {ref,i }}$ incerteza do valor certificado para o elemento i).

Cálculo do índice de translocação e tratamento estatístico - O índice de translocação (IT\%) dos elementos foi calculado utilizando a relação
(Abichequer et al. 2003): IT $=(\mathrm{PA} /(\mathrm{PA}+\mathrm{R})) \cdot 100$ $(\mathrm{PA}=$ concentração do elemento pela massa de matéria seca do sistema aéreo; $\mathrm{R}=$ concentração do elemento pela massa de matéria seca do sistema radicular).

O tratamento estatístico dos dados obtidos, a partir das plantas submetidas aos diferentes tratamentos (30 plantas tratamento $\left.{ }^{-1}\right)$, foi realizado pela análise da variância (ANOVA) ao nível de 5\% de significância, seguido pelo teste $t$ Student utilizando o programa BioEstat4.0.

\section{Resultados e Discussão}

Os resultados obtidos no material de referência INCT-TL-1 Tea Leaves e NIST SRM 1547 Peach Leaves, e os valores do certificado estão apresentados na tabela 1 . Os valores no material de referência INCT-TL-1 Tea Leaves indicam boa exatidão com porcentagens de erro relativo inferiores a $12,9 \%$. A precisão dos resultados foi avaliada por meio dos desvios padrão relativos e os valores observados variaram entre 2,3 a $9,3 \%$ indicando a reprodutibilidade. Os resultados para o material de referência NIST SRM 1547 Peach Leaves indicaram boa exatidão com erros relativos inferiores a $14,5 \%$ e os desvios padrão relativos inferiores a $14,6 \%$ indicando a reprodutibilidade dos resultados.

Os valores de Z-score (tabela 1) para os resultados dos materiais de referência INCT TL-1 Tea Leaves e NIST SRM 1547 Peach Leaves estão dentro da faixa de valores no intervalo considerado $\mid Z$-score $\mid<2$, nos materiais de referência analisados, indicando que os valores obtidos são concordantes com os valores certificados a 5\% de significância. Resultados semelhantes foram observados por Elias et al. (2006), em que a técnica mostrou precisão analítica na análise de folhas de espécies de Bromeliaceae (Aechmea coelestis (K. Koch) E. Morren, Billbergia amoema (Loddiges) Lindley, Canistropsis billbergioides (Schultes f.) Leme, Nidularium cf. inocentii, N. krisgreeniae Leme, Tillandsia stricta Solander, Vriesea carinata Wawra, V. ensiformis (Vellozo) Beer, $V$. incurvata Gaudichaud e V. vagans (L.B. Smith) L.B. Smith), visando o biomonitoramento de poluição, para os elementos Br, Ca, Ce, Co, Cs, Fe, K, Na, Rb, Sc, $\mathrm{Sr}$ e $\mathrm{Zn}$.

O aumento da concentração de zinco no meio de cultivo, incluindo as doses superiores aos da Resolução CONAMA, promoveram alterações no crescimento de Aechmea. blanchetiana, com aumento e acúmulo de massa de matéria fresca e seca nos sistemas aéreo e 
Tabela 1. Concentrações dos elementos Ca, Co, Fe, K e Zn nos materiais certificados INCT-TL-1 Tea Leaves e NIST SRM 1547 Peach Leaves. * Valor informativo; M: Média aritmética; DP: Desvio padrão; DPR: Desvio padrão relativo; Er: Erro relativo; n: Número de determinações; nd: Não determinado.

Table1. Concentration of the elements $\mathrm{Ca}, \mathrm{Co}, \mathrm{Fe}, \mathrm{K}$, and $\mathrm{Zn}$ in the certified materials INCT-TL-1 Tea Leaves and NIST SRM 1547 Peach Leaves. * Informative value; M: Arithmetic mean, DP: Standard deviation, DPR: Relative standard deviation; Er: Relative error; n: Number of determinations; nd: Not determined.

\begin{tabular}{|c|c|c|c|c|c|}
\hline \multirow{2}{*}{ Elementos } & \multicolumn{4}{|c|}{ INCT-TL-1 Tea Leaves } & \multirow{2}{*}{$\begin{array}{l}\text { Valores do certificado } \\
\text { (INCT, 2002) }\end{array}$} \\
\hline & $\mathrm{M} \pm \mathrm{DP}(\mathrm{n})$ & $\operatorname{DPR}(\%)$ & $\operatorname{Er}(\%)$ & Z-score & \\
\hline $\mathrm{Ca}(\%)$ & $0,56 \pm 0,04(13)$ & 7,1 & 3,8 & $-0,3$ & $0,582 \pm 0,052$ \\
\hline $\mathrm{Co}\left(\mu \mathrm{g} \mathrm{kg}^{-1}\right)$ & $409 \pm 38(12)$ & 9,3 & 5,7 & 0,4 & $387 \pm 42$ \\
\hline $\mathrm{Fe}\left(\mathrm{mg} \mathrm{kg}^{-1}\right)$ & $553 \pm 25(16)$ & 4,5 & nd & nd & $* 432$ \\
\hline $\mathrm{K}(\%)$ & $1,78 \pm 0,11(13)$ & 6,1 & 5,3 & 0,6 & $1,70 \pm 0,12$ \\
\hline $\mathrm{Zn}\left(\mathrm{mg} \mathrm{kg}^{-1}\right)$ & $39,2 \pm 0,9(14)$ & 2,3 & 12,9 & 1,6 & $34,7 \pm 2,7$ \\
\hline \multirow{2}{*}{ Elementos } & \multicolumn{4}{|c|}{ NIST SRM 1547 Peach Leaves } & Valores do certificado \\
\hline & $\mathrm{M} \pm \mathrm{DP}(\mathrm{n})$ & $\operatorname{DPR}(\%)$ & $\operatorname{Er}(\%)$ & Z-score & (NIST, 2003) \\
\hline $\mathrm{Ca}(\%)$ & $1,51 \pm 0,14(11)$ & 9,3 & 3,2 & $-0,30$ & $1,56 \pm 0,02$ \\
\hline $\mathrm{Co}\left(\mathrm{mg} \mathrm{kg}^{-1}\right)$ & $0,076 \pm 0,010(8)$ & 13,2 & nd & nd & $* 0,07$ \\
\hline $\mathrm{Fe}\left(\mathrm{mg} \mathrm{kg}^{-1}\right)$ & $220,7 \pm 17,7(13)$ & 8,0 & 1,2 & 0,12 & $218 \pm 14$ \\
\hline $\mathrm{K}(\%)$ & $2,6 \pm 0,2(11)$ & 7,7 & 7,0 & 0,80 & $2,43 \pm 0,03$ \\
\hline $\mathrm{Zn}\left(\mathrm{mg} \mathrm{kg}{ }^{-1}\right)$ & $20,5 \pm 3,0(12)$ & 14,6 & 14,5 & 0,86 & $17,9 \pm 0,4$ \\
\hline
\end{tabular}

radicular (tabela 2). No entanto, em estudo realizado por Giampaoli et al. (2012) com plantas de Aechmea blanchetiana submetidas às mesmas condições de cultivo, em MS modificado com Zn, e sem a poda das folhas e raízes, observou a diminuição no número de raízes e folhas, e nas massas de matéria seca foliar e radicular, indicando que a espécie apresenta sensibilidade à deficiência de zinco.

Os teores de $\mathrm{K}$ e Zn no sistema aéreo e $\mathrm{Ca}$, Co, $\mathrm{K}$ e $\mathrm{Zn}$ no sistema radicular (tabela 3 ) aumentaram com a elevação das concentrações de zinco no meio de cultivo, havendo diminuição nas concentrações de Co, com o aumento da concentração de Zn. A quantidade e a localização de acúmulo de zinco nas plantas podem variar de acordo com o teor do metal existente no meio e a espécie vegetal (Lasat et al. 2000). O aumento das concentrações de zinco no meio de cultivo diminuiu as concentrações de $\mathrm{Ca}, \mathrm{K}, \mathrm{Mg}, \mathrm{Cu}$ e $\mathrm{P}$ em folhas de Lolium perenne L. cv Apollo, em adição ao estresse causado pelo $\mathrm{Zn}$, a deficiência dos íons poderiam alterar diversos processos metabólicos como a fotossíntese, redução dos níveis de nitrato, neutralização de radiais ácidos, etc. (Bonnet et al. 2000). Estudos em Thlaspi caerulescens J. Presl \& C. Presl mostraram que, assim como em $A$. blanchetiana, houve acúmulo de Zn nos vacúolos das raízes da espécie, retardando a translocação do Zn e posterior fitotoxidez do sistema aéreo das plantas (Lasat et al. 2000). Estudo de nutrição mineral nos diferentes órgãos de Aechmea fasciata, mostrou que as folhas foram responsáveis por $43 \%$, o caule $28 \%$ e as raízes $29 \%$ do total de $\mathrm{Zn}$ acumulado na planta (Sanches 2009). As plantas A. blanchetiana acumularam $\mathrm{Zn}$ no sistema radicular

Tabela 2. Média das massas fresca e seca dos sistemas aéreos e radiculares por plântula e porcentagem da perda de umidade de Aechmea blanchetiana (Baker) L.B. Smith cultivada in vitro, em solução nutriente contendo diferentes concentrações de Zn. M: Média aritmética; DP: Desvio padrão; n: Número de plântulas; SA: Sistema aéreo; SR: Sistema radicular. As médias com letras distintas indicam diferenças significativas pelo teste $t$ Student $(p<0,05)$.

Table 2. Average of fresh and dry mass of aerial and root systems per plant and percentage of moisture loss from A. blanchetiana (Baker) L.B. Smith cultivated in vitro in nutrient solution containing different concentrations of $\mathrm{Zn}$. M: Arithmetic mean; DP: Standard deviation; $n$ : Number of seedlings; SA: Air System; SR: Root system. Means with different letters indicate significant differences by Student's t test $(p<0.05)$.

\begin{tabular}{ccc}
\hline $\begin{array}{l}\text { Tratamentos Zn } \\
\left(\mathrm{mg} \mathrm{L}^{-1}\right)\end{array}$ & $\begin{array}{c}\text { Massa seca SA }(\mathrm{g}) \\
\mathrm{M} \pm \mathrm{DP}\end{array}$ & $\begin{array}{c}\text { Massa seca SR } \\
(\mathrm{g}) \mathrm{M} \pm \mathrm{DP}\end{array}$ \\
\hline 0,00 & $0,113 \pm 0,011 \mathrm{dc}$ & $0,013 \pm 0,003 \mathrm{c}$ \\
0,18 & $0,095 \pm 0,010 \mathrm{~b}$ & $0,017 \pm 0,007 \mathrm{~b}$ \\
1,80 & $0,105 \pm 0,030 \mathrm{db}$ & $0,017 \pm 0,007 \mathrm{~b}$ \\
18,00 & $0,119 \pm 0,010 \mathrm{c}$ & $0,013 \pm 0,004 \mathrm{c}$ \\
180,00 & $0,199 \pm 0,042 \mathrm{a}$ & $0,021 \pm 0,004 \mathrm{a}$ \\
\hline
\end{tabular}


e no aéreo, provavelmente devido às características do cultivo in vitro, onde as folhas e raízes das plantas permaneceram em contato com o meio MS modificado tratado com Zn (líquido, sem adição de ágar). Giampaoli et al. (2012) observaram em A. blanchetiana que os teores variaram de 26,33 a 233,33 mg Zn kg-1 quando as plantas foram contaminadas com 0 a $275 \mu \mathrm{M} Z n$ e Elias et al. (2006) estudando a composição química foliar de 11 espécies de bromélias observaram valores de 11 a $57 \mu \mathrm{M} \mathrm{Zn} \mathrm{Kg}^{-1}$ em plantas coletadas em quatro diferentes unidades de conservação. A fitotoxidez por $\mathrm{Zn}$ acarreta inibição do crescimento e diminuição de produção de biomassa e é o resultado de interações

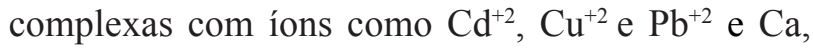
$\mathrm{Mg}, \mathrm{Fe}$ e $\mathrm{P}$, estando envolvida com a competição pela absorção, inativação de enzimas e o deslocamento de elementos essenciais de seus sítios funcionais (Rout \& Das 2003).

Os índices de translocação (tabela 4) aumentaram para os elementos $\mathrm{K}$ e Fe com a elevação das concentrações de $\mathrm{Zn}$ no meio de cultura, no entanto diminuíram para o $\mathrm{Zn}$ e Co. Os resultados estão de acordo com os obtidos por Paiva et al. (2003), nos quais o índice de translocação de $\mathrm{Zn}$ e Fe em

Tabela 3. Média das massas dos elementos nas amostras dos sistemas aéreo e radicular das plantas de Aechmea blanchetiana (Baker) L.B. Smith. SA: Sistema aéreo; SR: Sistema radicular. As médias com letras distintas indicam que há diferenças significativas pelo teste $t$ Student $(p<0,05)$.

Table 3. Average masses of elements in samples of aerial and root system of Aechmea blanchetiana (Baker) L.B. Smith. SA: Aerial system; SR: Root system. Means with different letters indicate that there are significant differences by Student's $t$ test $(p<0.05)$.

\begin{tabular}{|c|c|c|c|c|c|c|}
\hline \multicolumn{7}{|c|}{ Massas dos elementos em $\mu \mathrm{g} \mathrm{g}^{-1}$ de matéria seca } \\
\hline \multirow{2}{*}{\multicolumn{2}{|c|}{$\begin{array}{l}\text { Tratamentos } \\
\mathrm{Zn}\left(\mathrm{mg} \mathrm{L}^{-1}\right)\end{array}$}} & $\mathrm{Ca}$ & $\mathrm{Co}$ & $\mathrm{Fe}$ & $\mathrm{K}$ & $\mathrm{Zn}$ \\
\hline & & $\mathrm{M} \pm \mathrm{DP}$ & $\mathrm{M} \pm \mathrm{DP}$ & $\mathrm{M} \pm \mathrm{DP}$ & $\mathrm{M} \pm \mathrm{DP}$ & $\mathrm{M} \pm \mathrm{DP}$ \\
\hline \multirow{5}{*}{ AS } & 0,00 & $1648 \pm 315 \mathrm{a}$ & $0,42 \pm 0,03 \mathrm{a}$ & $264 \pm 13 \mathrm{a}$ & $32506 \pm 1133 b$ & $14 \pm 1 \mathrm{~d}$ \\
\hline & 0,18 & $1707 \pm 105 \mathrm{a}$ & $0,27 \pm 0,05 b$ & $273 \pm 15 \mathrm{a}$ & $33858 \pm 684 b$ & $26 \pm 1 \mathrm{~d}$ \\
\hline & 1,80 & $1719 \pm 489 \mathrm{a}$ & $0,26 \pm 0,06 \mathrm{~b}$ & $256 \pm 12 \mathrm{a}$ & $39937 \pm 4194 \mathrm{a}$ & $55 \pm 2 \mathrm{c}$ \\
\hline & 18,00 & $1804 \pm 264 \mathrm{a}$ & $0,30 \pm 0,01 \mathrm{~b}$ & $275 \pm 33 a$ & $31608 \pm 1859 b$ & $87 \pm 14 b$ \\
\hline & 180,00 & $2053 \pm 440 \mathrm{a}$ & $0,22 \pm 0,02 \mathrm{c}$ & $250 \pm 31 \mathrm{a}$ & $34632 \pm 3175 b$ & $218 \pm 28 \mathrm{a}$ \\
\hline \multirow{5}{*}{$\mathrm{RS}$} & 0,00 & $1553 \pm 100 \mathrm{c}$ & $0,96 \pm 0,02 \mathrm{c}$ & $637 \pm 5 b$ & $11857 \pm 149 \mathrm{c}$ & $42 \pm 1 \mathrm{~d}$ \\
\hline & 0,18 & $1059 \pm 20 \mathrm{~d}$ & $1,05 \pm 0,03 \mathrm{c}$ & $641 \pm 6 \mathrm{a}$ & $11410 \pm 83 c$ & $44,3 \pm 0,3 \mathrm{~d}$ \\
\hline & 1,80 & $1988 \pm 40 b$ & $1,02 \pm 0,03 \mathrm{c}$ & $470 \pm 5 d$ & $14213 \pm 122 b$ & $78,9 \pm 0,5 \mathrm{c}$ \\
\hline & 18,00 & $1913 \pm 2 b$ & $1,33 \pm 0,01 \mathrm{a}$ & $588 \pm 6 \mathrm{c}$ & $18011 \pm 137 \mathrm{a}$ & $200 \pm 1 b$ \\
\hline & 180,00 & $2604 \pm 250 \mathrm{a}$ & $1,20 \pm 0,09 b$ & $398 \pm 4 \mathrm{~d}$ & $10121 \pm 123 \mathrm{c}$ & $896 \pm 5 \mathrm{a}$ \\
\hline
\end{tabular}

Tabela 4. Índice de translocação do Ca, Co, Fe, K e Zn em plantas de Aechmea blanchetiana (Baker) L.B. Smith, cultivadas in vitro em meios contendo diferentes concentrações de Zn. M: Média aritmética; DP: Desvio padrão. As médias com letras distintas indicam diferenças significativas pelo teste $t$ Student $(p<0,05)$.

Table 4. Index translocation of $\mathrm{Ca}, \mathrm{Co}, \mathrm{Fe}, \mathrm{K}$, and $\mathrm{Zn}$ in plants of Aechmea blanchetiana (Baker) L.B. Smith, cultured in vitro in media containing different concentrations of $\mathrm{Zn}$. M: Arithmetic mean; SD: Standard deviation. Means with different letters indicate significant differences by Student's $t$ test $(p<0.05)$.

\begin{tabular}{cccccc}
\hline \multirow{2}{*}{$\begin{array}{c}\text { Tratamentos } \\
\text { Zn }\left(\text { mg L L }^{-1}\right)\end{array}$} & $\mathrm{Ca}$ & $\mathrm{Co}$ & $\mathrm{Fe}$ & $\mathrm{K}$ & $\mathrm{Zn}$ \\
\cline { 2 - 6 } & $\mathrm{M} \pm \mathrm{DP}$ & $\mathrm{M} \pm \mathrm{DP}$ & $\mathrm{M} \pm \mathrm{DP}$ & $\mathrm{M} \pm \mathrm{DP}$ & $\mathrm{M} \pm \mathrm{DP}$ \\
0,00 & $90 \pm 2 \mathrm{a}$ & $79 \pm 1 \mathrm{a}$ & $78 \pm 1 \mathrm{c}$ & $96 \pm 1 \mathrm{c}$ & $74 \pm 1 \mathrm{~b}$ \\
0,18 & $90 \pm 1 \mathrm{a}$ & $59 \pm 5 \mathrm{~b}$ & $70 \pm 1 \mathrm{~d}$ & $94 \pm 1 \mathrm{~b}$ & $77 \pm 1 \mathrm{~b}$ \\
1,80 & $84 \pm 3 \mathrm{~b}$ & $61 \pm 6 \mathrm{~b}$ & $77 \pm 1 \mathrm{c}$ & $95 \pm 1 \mathrm{~b}$ & $82 \pm 1 \mathrm{a}$ \\
18,00 & $90 \pm 1 \mathrm{a}$ & $67 \pm 1 \mathrm{c}$ & $81 \pm 2 \mathrm{~b}$ & $94 \pm 1 \mathrm{~b}$ & $80 \pm 2 \mathrm{a}$ \\
180,00 & $88 \pm 3 \mathrm{a}$ & $63 \pm 2 \mathrm{~b}$ & $86 \pm 2 \mathrm{a}$ & $97 \pm 1 \mathrm{a}$ & $69 \pm 3 \mathrm{c}$ \\
\hline
\end{tabular}


Cedrela fissilis Vell. (cedro) foi crescente com as doses do metal em solução nutritiva, mostrando que na presença de concentrações elevadas, o elemento $\mathrm{Zn}$ transloca para a parte aérea em maiores proporções $(52,4 \%)$ que a apresentada pelas plantas controle e que o metabolismo do $\mathrm{Fe}$ é inibido pelo aumento na concentração de Zn.

A técnica de cultivo in vitro de plantas permite isolar os efeitos dos metais pesados no metabolismo de plantas dos efeitos causados por outros fatores (Giampaoli et al. 2012) e ser responsiva à aplicação de nutrientes em meio de cultivo e contaminação por sais in vitro (Kanashiro 2009), apresenta as características para ser utilizada como um modelo no estudo de alterações metabólicas e de crescimento e desenvolvimento vegetal em função do estresse causado por metais pesados. As concentrações 1,8; 18 e $180 \mathrm{mg} \mathrm{Zn} \mathrm{L}^{-1}$, apesar de superiores aos índices permissíveis do CONAMA, apresentaram efeitos nutricionais no cultivo in vitro de $A$. blanchetiana e promoveram o aumento nos teores de $\mathrm{Zn}$ nos sistemas radicular e aéreo. Portanto, a espécie apresenta tolerância a altos níveis do metal, possibilitando a utilização de Aechmea blanchetiana no biomonitoramento de áreas contaminadas por $\mathrm{Zn}$.

\section{Agradecimentos}

A FAPESP (Fundação de Amparo à Pesquisa do Estado de São Paulo, Processo 2008/55680-8) e ao CNPq (Conselho Nacional de Desenvolvimento Científico e Tecnológico, Processo n ${ }^{\circ} 305776 / 2009-6$ ) pelo fomento a esta pesquisa.

\section{Literatura citada}

Abichequer, A.D., Bohnem, H. \& Anghinoni, I. 2003. Absorção, translocação e utilização de fósforo por variedades de trigo submetidas à toxidez de alumínio. Revista Brasileira de Ciências do Solo 27: $373-378$.

Bonnet, M., Camares, O. \& Veisseire, P. 2000. Effects of zinc and influence of Acremonium lolii on growth parameters, chlorophyll $a$ fluorescence and antioxidant enzyme activities of ryegrass (Lolium perenne L. cv Apollo). Journal of Experimental Botany 51: $945-953$.

CONAMA. Conselho Nacional do Meio Ambiente. Ministério do Meio Ambiente. Resolução no 357, de 17 de março de 2005.
Cunha, K.P.V., Nascimento, C.W.A., Pimentel, R.M.M., Accioly, A.M.A. \& Silva, A.J. 2008. Disponibilidade, acúmulo e toxidez de cádmio, zinco em milho cultivado em solo contaminado. Revista Ciência do Solo 32: 1319-1328.

De Soete, D., Gilbels, R. \& Hoste, J. 1972. Neutron activation analysis. Wiley Interscience, New York.

Elias, C., De Nadai Fernandes, E.A., França, E.J. \& Bacchi, M.A. 2006. Seleção de epífitas acumuladoras de elementos químicos na Mata Atlântica. Biota Neotropica 6: 1-9.

Flores, E.V. 1987. O uso de plantas como bioindicadoras de poluição no ambiente urbano-industrial: experiências em Porto Alegre, RS, Brasil. Tubinger Geographische Studien 96: 79-86.

Galvanese, M.S., Tavares, A.R., Aguiar, F.F.A., Kanashiro, S., Chu, E.P., Stancato, G.C. \& Harder, I.C.F. 2007. Efeito de ANA, 6-BA e agar na propagação in vitro de Aechmea blanchetiana (Baker) L.B. Smith, bromélia nativa da Mata Atlântica. Revista Ceres 54: 63-67.

Giampaoli, P., Tresmondim, F., Lima, G.P.P., Kanashiro, S., Alves, E.S., Domingos, M. \& Tavares, A.R. 2012. Analysis of tolerance to copper and zinc in Aechmea blanchetiana grown in vitro. Biologia Plantarum 56: 83-88.

Greenberg, R.R. 1984. Accuracy in standards preparation for neutron activation analysis. Journal of Radioanalytical and Nuclear Chemistry 179: 131-139.

IAEA. 2001. International Atomic Energy Agency. Quality aspects of research reactor operations for instrumental neutron activation analysis laboratory. IAEA, (IAEA - TECDOC - 1218), Viena.

INCT. 2002. Polish Certified Reference Material for Multielement Trace Analysis. Tea Leaves (INCT-TL-1). Institute of Nuclear Chemistry and Technology, Warsaw.

Kanashiro, S., Ribeiro, R. de C.S., Gonçalves, A.N., Demetrio, V.A., Jocys, T. \& Tavares, A.R. 2009. Effect of calcium on the in vitro growth of Aechmea blanchetiana (Baker) L.B. Smith plantlets. Journal of Plant Nutrition 32: 867-877.

Lasat, M.M., Pence, N.S., Garvin, D.F., Ebbs, S.D. \& Kochian, L.V. 2000. Molecular physiology of zinc transport in the $\mathrm{Zn}$ hyperaccumulator Thlaspi caerulescens. Journal of Experimental Botany 51: 71-79.

Lorenzi, H. \& Souza, H.M. 2001. Plantas Ornamentais no Brasil: arbustivas, herbáceas e trepadeiras. Instituto Plantarum, Nova Odessa.

Marschner, H. 1995. Mineral nutrition of higher plants. Academic Press, London.

Marsola, T., Miyazawa, M. \& Pavan, M.A. 2005. Acumulação de cobre e zinco em tecidos do feijoeiro em relação com o extraído do solo. Revista Brasileira de Engenharia Agrícola e Ambiental 9: 92-98. 
Murashige, T. \& Skoog, F. 1962. A revised medium for rapid growth and bio assay with tobacco tissue cultures. Phisyologia Plantarum 15: 473-497.

Navarro, G. 2003. Química Agricola. Mundi Prensa, Madri.

NIST. 2003. National Institute of Standards and Technology. Certificate of analysis. Standard Reference Material. 1547 Peach Leaves. Institute of Nuclear Chemistry and Technology, Warsaw.

Paiva, H.N., Carvalho, J.G., Siqueira, J.O. \& Corrêa, J.B.D. 2003. Teor, conteúdo e índice de translocação de nutrientes em mudas de cedro (Cedrela fissilis Vell.) submetidas a doses crescentes de zinco. Ciência Florestal 13: 1-10.

Rout, G.R. \& Das, P. 2003. Effect of metal toxicity on plant growth and metabolism: I. Zinc. Agronomie 23: 3-11.
Sanches, L.V.C. 2009. Desenvolvimento de Aechmea fasciata (Bromeliaceae) em função de diferentes saturações por bases no substrato e modos de aplicação da fertirrigação. Dissertação de Mestrado, Universidade Estadual Paulista "Júlio de Mesquita Filho", Botucatu.

Schüürmann, G. \& Markert, B. 1998. Ecotoxicology: ecological fundamentals, chemical exposure, and biological effects. John Wiley \& Sons, New York.

Tangahu, B.V., Abdullah, S.R.S., Basri, H., Idris, M., Anuar, N. \& Mukhlisin, M. 2011. A review on heavy metals $(\mathrm{As}, \mathrm{Pb}$, and $\mathrm{Hg}$ ) uptake by plants through phytoremediation. Internacional Journal of Chemical Engineering 2011: 1-31.

Zeitouni, C.F. 2003. Eficiência de espécies vegetais como fitoextratoras de cádmio, chumbo, cobre, níquel e zinco de um latossolo vermelho amarelo distrófico. Dissertação de Mestrado, Instituto Agronômico, Campinas. 
